\title{
Artificial Intelligence Techniques for Estimation of Optimum Weibull Parameters for Wind Speed Distribution
}

\author{
N.Natarajan, S.Dineshkumar, M.Shyam Sundar, M. Santhosh Kumar
}

\begin{abstract}
The main objective of this study is to estimate the optimum Weibull scale and shape parameters for wind speed distribution at three stations of the state of Tamil Nadu, India using Nelder-Mead, Broyden-Fletcher-Goldfarb-Shanno, and Simulated annealing optimization algorithms. An attempt has been made for the first time to apply these optimization algorithms to determine the optimum parameters. The study was conducted for long term wind speed data (38 years), short term wind speed data (5 years) and also with single year's wind speed data to assess the performance of the algorithm for different quantum of data. The efficiency of these algorithms are analyzed using various statistical indicators like Root mean square error (RMSE), Correlation coefficient (R), Mean absolute error (MAE) and coefficient of determination (R2). The results suggest that the performance of three algorithms is similar irrespective of the quantum of the dataset. The estimated Weibull parameters are almost similar for short term and long term dataset. There is a marginal variation in the obtained parameters when only single year's wind data is considered for the analysis. The Weibull probability distribution curve fits very well on the wind speed histogram when only single year's wind speed data is considered and fits marginally well when short term and long term wind speed data is considered.
\end{abstract}

Keywords :. Optimum Weibull parameters; Probability distribution curve; Nelder-Mead; Broyden-Fletcher-Goldfarb-Shanno; Simulated Annealing

\section{INTRODUCTION}

Attempt to reduce the carbon dioxide emissions from traditional energy resources have endorsed researchers around the world to look for opportunity renewable electricity sources. Nowadays, diverse renewable electricity assets along with wind, sun, tidal, geothermal, hydro strength, etc. are being utilized to satisfy the growing energy call for of the ever increasing population. Among these, wind energy has gained recognition over the decades on account that its freely available, cheap, environmental friendly, easily accessible, extractable and widely accepted [1]. As per International wind power association, the overall capability

Revised Manuscript Received on December 05, 2019.

* * Correspondence Author

N. Natarajan*, Department of Civil Engineering, Dr. Mahalingam college of engineering and Technology, Pollachi - 642003, Tamil Nadu, India. Email: itsrajan2002@yahoo.co.in

S. Dineshkumar, Department of Civil Engineering, Dr. Mahalingam college of engineering and Technology, Pollachi - 642003, Tamil Nadu, India. Email: itsrajan2002@yahoo.co.in

M. Shyam Sundar, Department of Civil Engineering, Dr. Mahalingam college of engineering and Technology, Pollachi - 642003, Tamil Nadu, India.

M. Santhosh Kumar, Department of Civil Engineering, Dr. Mahalingam college of engineering and Technology, Pollachi - 642003, Tamil Nadu, India. of all wind mills set up global by the end of 2017 has reached $546 \mathrm{GW}$. China possesses the most important wind strength marketplace with a wind capacity of $188 \mathrm{GW}$. Among different international locations, US has reached $89 \mathrm{GW}$, Germany has $56 \mathrm{GW}$, India has $32.9 \mathrm{GW}$, UK has $17.9 \mathrm{GW}$, Brazil has $12.8 \mathrm{GW}$, and France has $13.8 \mathrm{GW}$ [2].

Wind speed data analysis plays a critical role in wind power generation and development initiatives. One of the most essential elements of wind resource evaluation is to represent the wind speed primarily based on a particular probability distribution. This aids in the transformation of the discrete records into a continuous distribution. During this process, the wind velocities are collected into bins and a particular opportunity distribution that best fits the histogram is recognized. Two parameter Weibull and Rayleigh distributions are the most normally and widely used [3-11].

The most critical issue with the application of the Weibull distribution is the estimation of the Weibull scale parameter c and shape parameter $\mathrm{k}$ [12]. Numerous techniques are used to estimate these parameters. Dorvlo [13] adopted the Chi-square technique to estimate the Weibull parameters for four stations in Oman and Kingdom of Saudi Arabia. Silva [14] used the equal energy technique and square error diminution power technique to determine the Weibull parameters. Akdag and Dinler [15] performed a comparative study with energy pattern factor technique, graphical technique and most likelihood technique and terminated that the energy pattern method to be the appropriate. Rocha et al. [16] performed comparison with seven numerical strategies for the evaluating the strength in the determination of the Weibull parameters for the wind speed data collected in Camocim and Paracuru sites of Brazil from August 2004 and April 2006.

In some cases, these numerical techniques do now not provide reasonable results [17]. This entreated the researchers to assess the efficacy of heuristic optimization techniques in the estimation of the Weibull parameters. Rahmani et al. [18] used particle swarm optimization (PSO) for the wind speed evolved in Binaloud wind farm.

Barbosa [19] used the Harmony search (HS) algorithm for two Brazilian regions for the estimation of the Weibull parameters. Wang et al. [20] used Cuckoo seek optimization (CSO) and Ant Colony optimization (ACO) to predict the wind velocity in four stations in China. Andrade et al. [17]

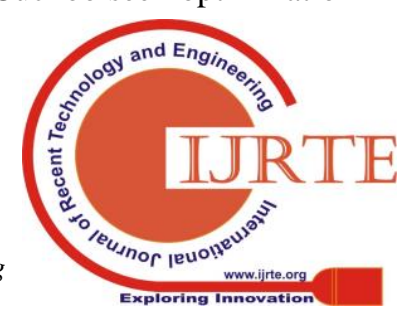


analyzed four heuristic optimization strategies, specifically, Ant Colony optimization, Cuckoo search optimization, Harmony seek optimization and Particle Swarm optimization for deducing the Weibull parameters for the wind speed of Petrolina, Triunfo and Sao Martinho da Serra areas of Brazil. They determined that the Ant Colony technique to be the most efficient method for Triunfo and Sao Martinho da Serra and Cuckoo search technique to be the maximum appropriate for Petrolina. Wang et al. [21] used a brand new optimization algorithm, Grey Wolf optimizer in addition to CSO, PSO and ACO for the determination of the Weibull parameters at three sites in Bohaiwan, China. They concluded GWO to be the most efficient approach for the estimation of the Weibull parameters. Thus, it is evident from the literature that only a handful of studies have been performed to assess the parameters of the Weibull distribution using optimization algorithms.

In this study, an attempt has been made for the first time to use Nelder-Mead (NM), Broyden-Fletcher-Goldfarb-Shanno (BFGS), and Simulated Annealing (SANN) optimization algorithms for the estimation of Weibull parameters for three sites located in the state of Tamil Nadu, India. Moreover, the optimum Weibull parameters were estimated using long term (38 years), short term (5 years) and single year's wind speed data to evaluate the performance of the algorithm for various quantum of wind speed data. As far as the author's knowledge is considered, the estimation of optimum Weibull parameters on the quantum of dataset has not been explored. The main objective of this study is to estimate the optimum Weibull scale and shape parameters for wind speed distribution at three stations of the state of Tamil Nadu, India using Nelder-Mead, Broyden-Fletcher-Goldfarb-Shanno, and Simulated annealing optimization algorithms.

\section{STUDY AREA AND WIND SPEED DATA}

Tamil Nadu is state located in India. Chennai is the capital city of the state. The state lies in the southernmost region of the Indian subcontinent. The climate of the state fluctuates from sub-humid to semi-arid. The state is heavily dependent on the monsoon rainfall for its water requirements. The geographical locations of the stations used in this study are shown in the map (Figure 1) using a square box.

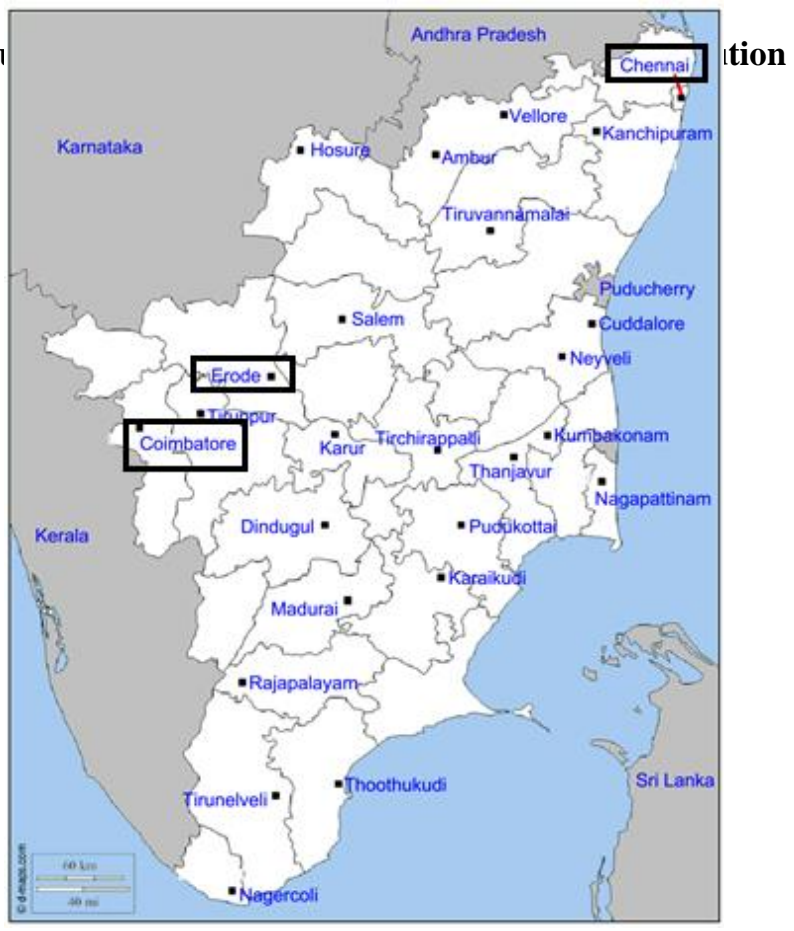

Fig. 1. Geographical location of the stations in Tamil Nadu, India

TABLE - I: GEOGRAPHICAL DETAILS OF THE

\begin{tabular}{|l|l|l|l|l|}
\hline S.No. & Location & Latitude & Longitude & Altitude (m) \\
\hline 1 & Chennai & $13.08 \mathrm{~N}$ & $80.27 \mathrm{E}$ & 13 \\
\hline 2 & Coimbatore & $11.01 \mathrm{~N}$ & $76.95 \mathrm{E}$ & 420 \\
\hline 3 & Erode & $11.34 \mathrm{~N}$ & $77.71 \mathrm{E}$ & 169 \\
\hline
\end{tabular}

\section{SELECTED STATIONS}

Table 1 provides the geographical details of Chennai, Coimbatore and Erode.

Hourly mean wind speed data recorded at height of $50 \mathrm{~m}$ above ground level was obtained from MERRA -2 reanalysis database (NASA) for a period of 38 years and 5 months from Jan 1980 to May 2018. Table 2 provides the annual mean, maximum, standard deviation, skewness and kurtosis calculated based on the wind speed data collected over the long term period.

TABLE- II: STATISTICAL SUMMARY OF LONG TERM WIND SPEED DATA

\begin{tabular}{|l|l|l|l|l|l|l|}
\hline $\begin{array}{l}\text { S. } \\
\mathbf{N} \\
\mathbf{0}\end{array}$ & Location & $\begin{array}{l}\text { Mean } \\
(\mathbf{m} / \mathbf{s})\end{array}$ & $\begin{array}{l}\text { Maxim } \\
\mathbf{u m} \\
(\mathbf{m} / \mathbf{s})\end{array}$ & $\begin{array}{l}\text { Stand } \\
\text { ard } \\
\text { devia } \\
\text { tion } \\
(\mathbf{m} / \mathbf{s})\end{array}$ & $\begin{array}{l}\text { Skewn } \\
\text { ess }\end{array}$ & $\begin{array}{l}\text { Kurtos } \\
\text { is }\end{array}$ \\
\hline 1 & Chennai & 5.41 & 7.43 & 0.81 & 0.0691 & 0.3073 \\
\hline 2 & Coimbatore & 4.72 & 8.17 & 1.39 & 0.5197 & 0.3379 \\
\hline 3 & Erode & 4.34 & 7.49 & 1.18 & 0.6877 & 0.7386 \\
\hline
\end{tabular}


The mean wind speed of Chennai, Coimbatore and Erode are found to be $5.41 \mathrm{~m} / \mathrm{s}, 4.72 \mathrm{~m} / \mathrm{s}$ and $4.34 \mathrm{~m} / \mathrm{s}$ respectively. The maximum wind corresponding to the three stations are $7.43 \mathrm{~m} / \mathrm{s}, \quad 8.17 \mathrm{~m} / \mathrm{s}$ and $7.49 \mathrm{~m} / \mathrm{s}$ respectively. Thus Coimbatore has the maximum wind speed of $8.17 \mathrm{~m} / \mathrm{s}$ while Chennai the highest mean wind speed of $5.41 \mathrm{~m} / \mathrm{s}$ based on the data considered for this study.

The probability density function is given by the following expression [18,24]:

$$
f(v)=\frac{k}{c}\left(\frac{v}{c}\right)^{k-1} \exp \left[-\left(\frac{v}{c}\right)^{k}\right]
$$

Where $\mathrm{v}$ is the wind speed, $\mathrm{c}$ is the scale parameter and $\mathrm{k}$ is the shape parameter.

\section{Optimization Methods}

Three optimization methods are being used in this study, namely, NM, BFGS and SANN. A brief description of each of these methods is provided below.

\section{A. Nelder-Mead optimization algorithm}

This algorithm is applicable for unconstrained problems. Other names of this algorithm include downhill simplex method and amoeba method. The algorithm is illustrated by means of a flowchart provided in Figure 2.

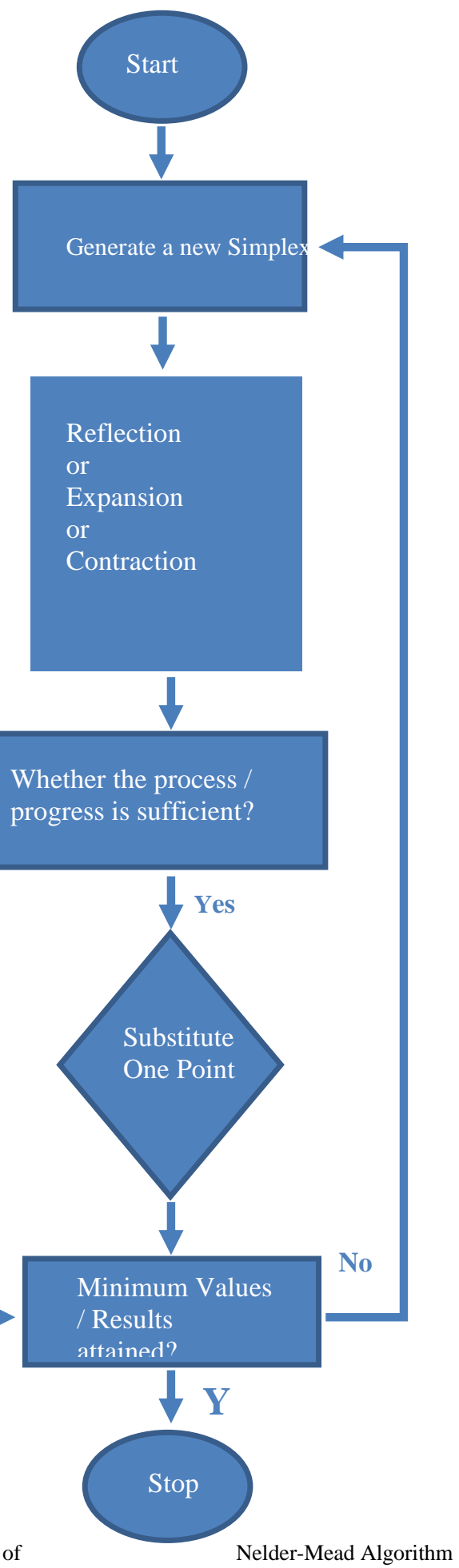

Fig. 2. Flowchart of

\section{B. BFGS algorithm}

In numerical optimization, the

Broyden-Fletcher-Goldfarb-Shanno (BFGS) algorithm is a method for solving nonlinear optimization problems. This algorithm is explained using the flowchart given below in Figure.3. 


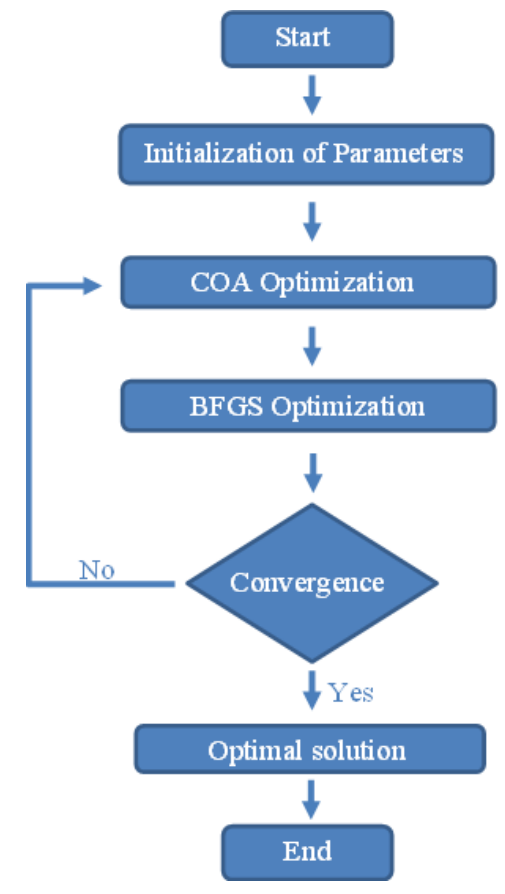

Fig. 3. Flowchart of BFGS algorithm

\section{Simulated annealing}

Simulated annealing (SA) is a technique for approximating the global optimum of a given function. The flowchart for this algorithm is provided in Figure 4 below.

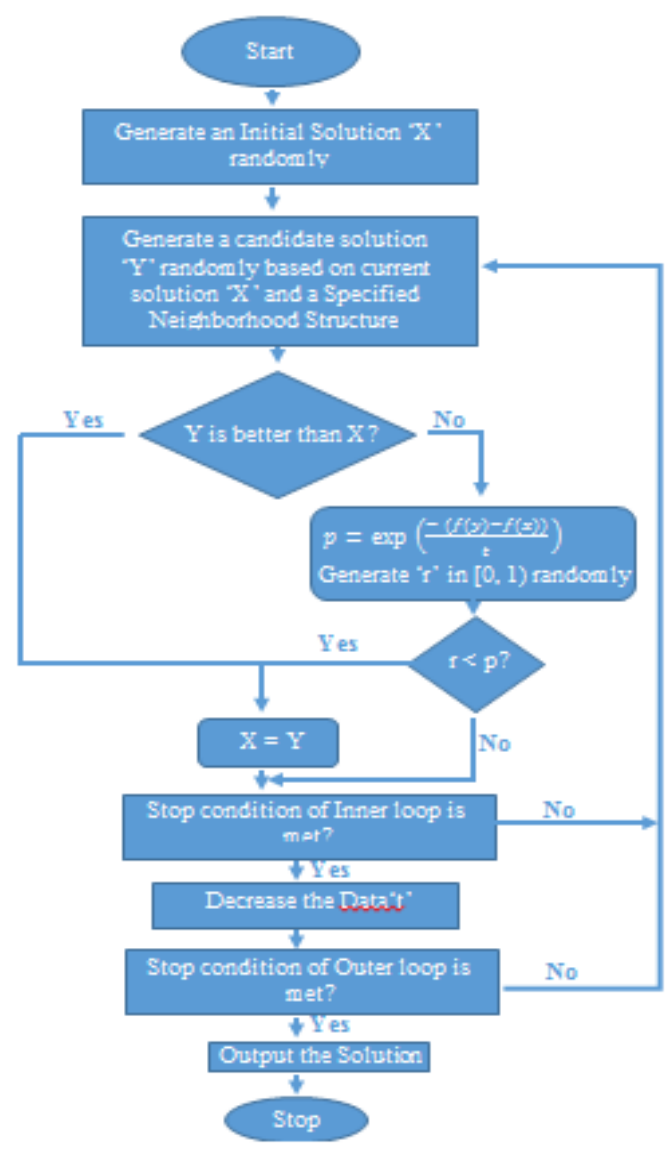

Fig. 4. Flowchart of the Simulated Annealing optimisation algorithm

\section{STATISTICAL ANALYSIS}

To evaluate the efficiency of the optimization methods used in this study, the following statistical analysis tools have been used: Root mean square error (RMSE), Correlation coefficient (R), Mean absolute error (MAE) and coefficient of determination (R2):

1. Root mean square error (RMSE)

$$
\text { RMSE }=\sqrt{\frac{\sum_{i=1}^{n}\left(P_{i}-o_{i}\right)^{2}}{n}}
$$

2. Pearson correlation coefficient

$$
\begin{aligned}
& \mathbf{R}= \\
& n\left(\sum_{i=1}^{n} o_{i} P_{i}\right)-\left(\sum_{i=1}^{n} o_{i}\right) \cdot\left(\sum_{i=1}^{n} P_{i}\right) \\
& \sqrt{\left(n \sum_{i=1}^{n} o_{i}^{2}-\left(\sum_{i=1}^{n} o_{i}\right)^{2}\right) \cdot\left(n \sum_{i=1}^{n} P_{i}^{2}-\left(\sum_{i=1}^{n} P_{i}\right)^{2}\right)}
\end{aligned}
$$

3. Mean Absolute Error (MAE)

$$
\operatorname{MAE}=\frac{1}{n} \sum_{i=1}^{n}\left|P_{i}-O_{i}\right|
$$

Where Pi indicates the calculated frequencies and $\mathrm{Oi}$ indicates the observed/actual frequencies, $\mathrm{n}$ is the sample size.

4. Coefficient of determination (R2)

$$
\mathbf{R}^{2}=\frac{\left[\sum_{i=1}^{n}\left(o_{i}-\overline{o_{l}}\right) \cdot\left(P_{i}-\overline{P_{l}}\right]^{2}\right.}{\sum_{i=1}^{n}\left(o_{i}-\overline{o_{i}}\right) \Sigma_{i=1}^{n}\left(P_{i}-\overline{P_{1}}\right)}
$$

\section{RESULTS AND DISCUSSION}

In this study, NM, BFGS and SANN optimization algorithms have been used to determine the optimal Weibull parameters for the wind speed data of three stations in the state of Tamil Nadu, India. The scale $\mathrm{c}$ and shape $\mathrm{k}$ parameters obtained for the three stations along with the RMSE, R, MAE and $\mathrm{R} 2$ values are provided in Tables 3-5 below. 
TABLE - III: PERFORMANCE EVALUATION OF NM, BFGS AND SANN FOR CHENNAI

\begin{tabular}{|l|c|c|c|c|c|c|}
\hline $\begin{array}{c}\text { Optimization } \\
\text { Method }\end{array}$ & $\begin{array}{c}\text { Scale } \\
\text { c }\end{array}$ & $\begin{array}{c}\text { Shap } \\
\text { e k }\end{array}$ & RMSE & R & MAE & R2 \\
\hline NM & 6.0431 & 2.9060 & 0.4524 & 0.6362 & 0.3867 & 0.4048 \\
\hline BFGS & 6.0435 & 2.9062 & 0.4524 & 0.6362 & 0.3867 & 0.4047 \\
\hline SANN & 6.0417 & 2.9032 & 0.4523 & 0.6359 & 0.3867 & 0.4044 \\
\hline
\end{tabular}

TABLE -IV: PERFORMANCE EVALUATION OF NM, BFGS AND

SANN FOR COIMBATORE

\begin{tabular}{|l|c|c|c|c|c|c|}
\hline $\begin{array}{c}\text { Optimization } \\
\text { Method }\end{array}$ & $\begin{array}{c}\text { Scale } \\
\mathbf{c}\end{array}$ & $\begin{array}{c}\text { Shape } \\
\mathbf{k}\end{array}$ & $\mathbf{R M S E}$ & $\mathbf{R}$ & MAE & R2 \\
\hline NM & 5.2993 & 2.2733 & 0.4482 & 0.6481 & 0.3821 & 0.4200 \\
\hline BFGS & 5.2990 & 2.2733 & 0.4482 & 0.6481 & 0.3821 & 0.4200 \\
\hline SANN & 5.2992 & 2.2727 & 0.4482 & 0.6480 & 0.3821 & 0.4199 \\
\hline
\end{tabular}

TABLE- V: PERFORMANCE EVALUATION OF NM, BFGS AND SANN FOR ERODE

\begin{tabular}{|l|c|c|c|c|c|c|}
\hline $\begin{array}{c}\text { Optimization } \\
\text { Method }\end{array}$ & $\begin{array}{c}\text { Scale } \\
\mathbf{c}\end{array}$ & $\begin{array}{c}\text { Shape } \\
\mathbf{k}\end{array}$ & $\mathbf{R M S E}$ & $\mathbf{R}$ & MAE & $\mathbf{R 2}$ \\
\hline NM & 4.8857 & 2.2835 & 0.4337 & 0.6832 & 0.3729 & 0.4668 \\
\hline BFGS & 4.8856 & 2.2832 & 0.4337 & 0.6832 & 0.3729 & 0.4667 \\
\hline SANN & 4.8850 & 2.2833 & 0.4336 & 0.6832 & 0.3728 & 0.4668 \\
\hline
\end{tabular}

The optimum scale and shape parameters obtained from NM, BFGS and SANN for Chennai is around 6.04 and 2.9. For Coimbatore, it is around 5.29 and 2.27, and for Erode it is around 4.88 and 2.28. The RMSE, R, MAE and R2 values are also very much similar for NM, BFGS and SANN. The graphical representation of the Weibull probability distribution curve fitted on the histogram of Chennai, Coimbatore and Erode in provided in Figure 5.

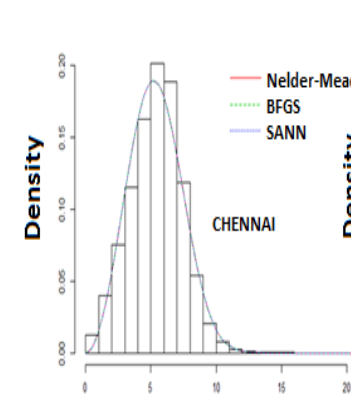

Wind speed $(\mathrm{m} / \mathrm{s})$

Wind speed $(\mathrm{m} / \mathrm{s})$

Wind speed $(\mathrm{m} / \mathrm{s})$

Fig. 5. Comparison of Weibull distribution curve obtained from NM, BFGS and SANN fitted on the wind speed histogram of Chennai, Coimbatore and Erode (38 years wind speed data)

It is observed from Figure 5 that the performance of NM, BFGS and SANN are similar to each other for all the stations. The probability distribution curve for Chennai is approximately symmetric as the skewness value is in the range of -0.5 to 0.5 . The probability distribution curve for Coimbatore and Erode are moderately skewed as the skewness value is in the range of 0.5 to 1.0. Moreover, the probability distribution curve marginally fits well for Chennai and poorly for Coimbatore and Erode.
To analyse the influence of quantum of data on the performance of the optimization algorithms in the estimation of optimum Weibull parameters, the same study was performed with only one year and five years of wind speed data. The optimum Weibull parameters obtained for Chennai, Coimbatore and Erode is provided in Table 6 below.

TABLE -VI: WEIBULL SCALE AND SHAPE PARAMETERS FOR ALL

STATIONS BASED ON ONE AND FIVE YEARS' DATA USING NM, BFGS AND SANN

\begin{tabular}{|c|c|c|c|c|c|c|}
\hline \multicolumn{7}{|c|}{ Wind speed data of 2017} \\
\hline \multirow{3}{*}{$\begin{array}{l}\text { Optimisation } \\
\text { methods }\end{array}$} & \multicolumn{6}{|c|}{ Station } \\
\hline & \multicolumn{2}{|c|}{ Chennai } & \multicolumn{2}{|c|}{ Coimbatore } & \multicolumn{2}{|c|}{ Erode } \\
\hline & Scale & Shape & Scale & Shape & Scale & Shape \\
\hline NM & 5.6815 & 2.8313 & 4.9592 & 2.3018 & 4.6136 & 2.3227 \\
\hline BFGS & 5.6813 & 2.8315 & 4.9594 & 2.3020 & 4.6132 & 2.3227 \\
\hline SANN & 5.6823 & 2.8336 & 4.9603 & 2.3042 & 4.6142 & 2.3234 \\
\hline \multicolumn{7}{|c|}{ Wind speed data of 1980-1984 } \\
\hline \multirow{3}{*}{$\begin{array}{l}\text { Optimisation } \\
\text { methods }\end{array}$} & \multicolumn{6}{|c|}{ Station } \\
\hline & \multicolumn{2}{|c|}{ Chennai } & \multicolumn{2}{|c|}{ Coimbatore } & \multicolumn{2}{|c|}{ Erode } \\
\hline & Scale & Shape & Scale & Shape & Scale & Shape \\
\hline NM & 6.1858 & 3.0991 & 5.2442 & 2.2531 & 4.8624 & 2.2727 \\
\hline BFGS & 6.1858 & 3.0988 & 5.2446 & 2.2532 & 4.8626 & 2.2727 \\
\hline SANN & 6.1875 & 3.1001 & 5.2427 & 2.2534 & 4.8629 & 2.2734 \\
\hline
\end{tabular}

It is observed from Table 6 that the optimum Weibull scale and shape parameters based on five years of wind speed data is akin to that obtained based on long term 38 years wind speed data provided in Table 3 . Therefore, the performance of the optimization algorithms remains unaffected when long term wind speed data is considered for the estimation of Weibull parameters. On the other hand, when only 2017 year's wind speed data is considered for the estimation of the optimum Weibull parameters, there is a marginal variation in the values obtained. Thus, the optimum Weibull parameters obtained varies with the quantum of wind speed data considered for the analysis. The graphical representation of the Weibull probability distribution curve fitted on the histogram of Chennai, Coimbatore and Erode in provided in rigures 6 and 7. 
NM, BFGS and SANN fitted on the wind speed histogram of Chennai, Coimbatore and Erode (5 years wind speed data)

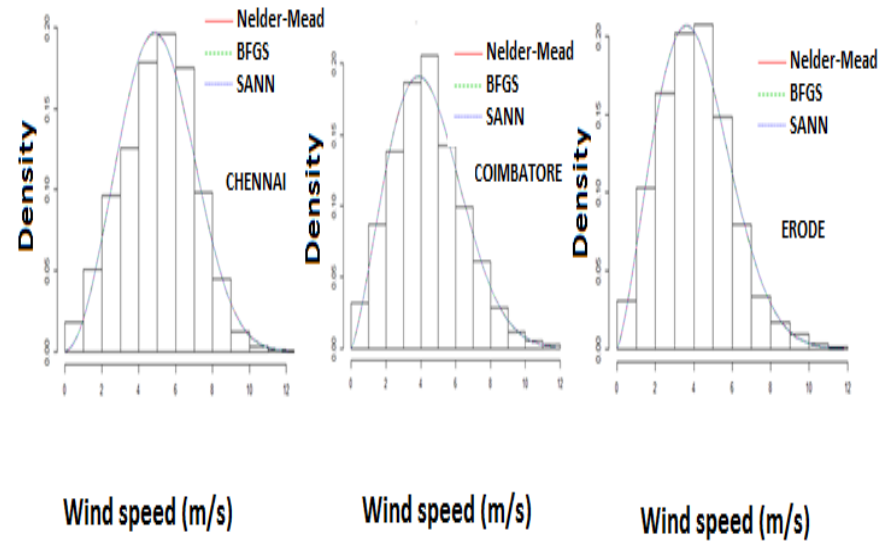

Fig. 7. Comparison of Weibull distribution curve obtained from NM, BFGS and SANN fitted on the wind speed histogram of Chennai, Coimbatore and Erode (2017's wind speed data)

Comparison of Figures 6 and 7 shows that in Figure 6, the Weibull distribution curves fit the histogram marginally but in Figure 7, although performance of the optimization algorithms being similar, the distribution curves fit well with the histogram. Thus, the performance of the algorithms is better when the dataset is trivial.

\section{CONCLUSION}

An attempt has been made for the first time to apply these optimization algorithms to determine the optimum parameters. The study was conducted for long term wind speed data (38 years), short term wind speed data (5 years) and also with single year's wind speed data to assess the performance of the algorithm for different quantum of data. The efficiency of these algorithms are analysed using various statistical indicators like Root mean square error (RMSE), Correlation coefficient (R), Mean absolute error (MAE) and coefficient of determination (R2). The conclusions derived from this study are as follows:

1. The optimum scale and shape parameters obtained from NM, BFGS and SANN for Chennai is around 6.04 and 2.9. For Coimbatore, it is around 5.29 and 2.27, and for Erode it is around 4.88 and 2.28, when long term data of 38 years is considered.

2. The optimum scale and shape parameters obtained from NM, BFGS and SANN for Chennai is around 6.1 and 3.1. For Coimbatore, it is around 5.24 and 2.25, and for Erode it is around 4.86 and 2.27, when short term data of 10 years is considered.

3. The optimum scale and shape parameters obtained from NM, BFGS and SANN for Chennai is around 5.68 and 2.83. For Coimbatore, it is around 4.96 and 2.3, and for Erode it is around 4.61 and 2.32, when single year's data is considered.

4. Performance of three algorithms is similar irrespective of the quantum of the dataset.

5. The estimated Weibull parameters are almost similar for short term and long term dataset and there is a marginal variation in the obtained parameters when only single year's wind data is considered for the analysis.

6. The Weibull probability distribution curve fits very well on the wind speed histogram when only single year's wind speed data is considered and fits marginally well when short term and long term wind speed data is considered.

\section{REFERENCES}

1. S. Rehman, "Wind energy resources assessment for Yanbo, Saudi Arabia", Energy Conversion Management, vol.45, pp.2019-2032, 2004.

2. https://wwindea.org/information-2/information/

3. M. Mirhosseini, F. Sharifi, A. Sedaghat, "Assessing the wind energy potential locations in province of Semnan in Iran", Renewable and sustainable energy reviews, vol. 15 (1), pp. 449-59, 2011.

4. M. Teimouri, S.M.Hoseini, S.Nadarajah, "Comparison of estimation methods for the Weibull distribution", Statistics, vol. 47(1), pp. 93-109, 2013.

5. M. Gökçek, A. Bayülken, S. Bekdemir, "Investigation of wind characteristics and wind energy potential in Kirklareli, Turkey", Renewable Energy, Vol.32 (10), pp. 1739-52, 2007.

6. T.R. Ayodele, A.A. Jimoh, J.L. Munda, J.T. Agee JT, "Wind distribution and capacity factor estimation for wind turbines in the coastal region of South Africa", Energy Conversion Management, Vol. 64, pp. 614-25, 2012.

7. S. Rehman, A.M. Mahbub, J.P.Meyer, L.M. Al-Hadhrami, "Wind Speed Characteristics and Resource Assessment using Weibull Parameters", International Journal of Green Energy, Vol. 9, pp. 800-814, 2012.

8. H.S. Bagiorgas, G. Mihalakakou, S. Rehman, L.M. Al-Hadhrami, "Wind Power Potential Assessment for Seven Buoys Data Collection Stations in Aegean Sea Using Weibull Distribution Function", J. Renew.Sust. Energ., Vol. 4(1), pp. 013119-013134, 2012.

9. M. Bassyouni, A.G. Saud, U. Javaid, M. Awais, S. Rehman, S.M.S Abdel-Hamid, M.H. Abdel-Aziz, A. Abouel-Kasem, H. Shafeek, "Assessment and analysis of Wind Power Resource using Weibul Parameters", Energ. Explor.Exploit., Vol.33(1), pp. 105 - 122, 2015.

10. H.S. Bagiorgas, G. Mihalakakou, S. Rehman, L.M. Al-Hadhrami, "Wind Power Potential Assessment for Three Buoys Data Collection Stations in Ionian Sea Using Weibull Distribution Function", Int. J Green Energy, Vol. 13(7), pp.703-714, 2016.

11. M.A. Baseer, J.P. Meyer, S. Rehman, M. Alam Md., "Wind power characteristics of seven data collection sites in Jubail, Saudi Arabia using Weibull parameters", Renew. Energ., Vol. 102, pp. 35-49, 2017.

12. C.F. de Andrade, L.F. dos Santos, M.V.S. Macedo, P.A.C. Rocha, F.F. Gomes, "Four heuristic optimization algorithms applied to wind energy: determination of Weibull curve parameters for three Brazilian sites", International journal of energy and environmental engineering (2018), https://doi.org/10.1007/s40095-018-0285-5.

13. A.S. Dorvlo, "Estimating wind speed distribution", Energy Conversion and Management, Vol. 43(17), pp. 2311-2318, 2002.

14. G.R. Silva, "Características de vento da região nordeste, análise, modelagem e aplicações para projetos de centrais eólicas”, Master's thesis, Federal University of Pernambuco, Recife, 2003.

15. S.A. Akdag, A. Dinler, "A new method to estimate weibull parameters for wind energy applications", Energy Conversion and Management, Vol. 50(7), pp. 1761-1766, 2009.

16. P.A.C.Rocha, R.C. Souza, C.F. Andrade, M.E.V. Silva, "Comparison of seven numerical methods for determining weibull parameters for wind energy generation in the northeast region of Brazil", Applied Energy, Vol. 89(1), pp. 395-400, 2012.

17. C.F Andrade, M.F.H. Neto, P.A.C. Rocha, M.E.V. Silva, "An efficiency comparison of numerical methods for determining weibul parameters for wind energy applications: a new approach applied to the northeast region of Brazil", Energy Conversion and Management, Vol. 86, pp. 801-808, 2014.

18. R. Rahmani, R. Yusof, M.S. Mahmoudian, S. Mekhilef, "Hybrid technique of ant colony and particle swarm optimization for short term wind energy forecasting", J. Wind Eng. Ind. 
Aerodyn., Vol. 123, pp. 163-170, 2013.

19. H.P. Barbosa, "Utilização da busca harmônica no ajuste da curva de weibull aplicado a dados de vento", Master's thesis, Mechanical Engineering Course, Mechanical Engineering Department, Federal University of Ceará, Fortaleza (2015).

20. Z. Wang, C.Wang, J. Wu, "Wind energy potential assessment and forecasting research based on the data pre-processing technique and swarm intelligent optimization algorithms", Sustainability, Vol. 8(11), pp.1-32, 2016.

21. J. Wang, X. Huang, Q. Li, X. Ma, "Comparison of seven methods for determining the optimal statistical distribution parameters : A case study of wind energy assessment in the large-scale wind farms if China", Energy, Vol. 164, pp. 432-448, 2018.

\section{AUTHORS PROFILE}

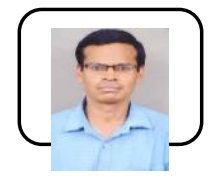

Dr. N. Natarajan is working as an associate professor in the department of Civil Engineering, Dr. Mahalingam College of engineering and technology, Pollachi, Tamil Nadu, India. His research interests include contaminant transport modeling, environmental pollution, and water resources.

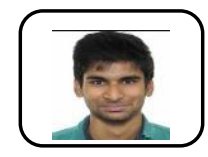

Mr. S. Dineshkumar is working as an assistant professo in the department of Civil Engineering,, Dr. Mahalingam College of engineering and technology, Pollachi, Tamil $\mathrm{Nadu}$, India. His research interests include geotechnical engineering and geohydraulics.

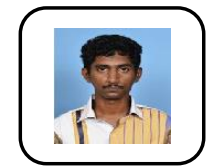

Mr. M. Shyam Sundar is an undergraduate studen pursuing her bachelors degree in Civil Engineering at Dr. Mahalingam college of engineering and technology, Pollachi, Tamil Nadu, India.

Mr. M. Santhosh Kumar is an undergraduate student pursuing her bachelors degree in Civil Engineering at Dr. Mahalingam college of engineering and technology, Pollachi, Tamil Nadu, India. 